\title{
Saba Mahmood, Politique de la piété : le féminisme à l'épreuve du renouveau islamique
}

Paris, La Découverte, coll. « Textes à l'appui / Genre \& sexualité », 2009

[2005], $312 \mathrm{p}$.

Marion Maudet et Guillaume Roucoux

\section{(2) OpenEdition}

Journals

Édition électronique

URL : http://journals.openedition.org/assr/26491

DOI : $10.4000 /$ assr.26491

ISSN : $1777-5825$

Éditeur

Éditions de l'EHESS

Édition imprimée

Date de publication : 31 décembre 2014

Pagination : 243

ISBN : 978-2-7132-2467-6

ISSN : 0335-5985

Référence électronique

Marion Maudet et Guillaume Roucoux, « Saba Mahmood, Politique de la piété : le féminisme à

l'épreuve du renouveau islamique », Archives de sciences sociales des religions [En ligne], 168 | 2014,

mis en ligne le 11 mai 2015, consulté le 22 septembre 2020. URL : http://journals.openedition.org/ assr/26491; DOl : https://doi.org/10.4000/assr.26491

Ce document a été généré automatiquement le 22 septembre 2020.

() Archives de sciences sociales des religions 


\section{Saba Mahmood, Politique de la piété : le féminisme à l'épreuve du renouveau islamique}

Paris, La Découverte, coll. « Textes à l'appui / Genre \& sexualité », 2009 [2005], $312 \mathrm{p}$.

Marion Maudet et Guillaume Roucoux

\section{RÉFÉRENCE}

Saba Mahmood, Politique de la piété : le féminisme à l'épreuve du renouveau islamique, Paris, La Découverte, coll. « Textes à l'appui / Genre \& sexualité », 2009 [2005], 312 p. 
1 Saba Mahmood est professeur d'anthropologie à l'Université de Berkeley. C'est au Pakistan où elle est née, qu'elle découvre après une forte période de revigoration nationaliste le phénomène d'islamisation et ses «lois discriminatoires contre les femmes » à l'origine de cet ouvrage. Traitant de l'engagement de certaines d'entre elles en Islam et de leur capacité d'agir (agency), Politique de la Piété s'inscrit au croisement des études de genre et des religions, dans une perspective marxiste critique et féministe.

L'enquête ethnographique fut menée par l'auteur en Égypte, dans la ville du Caire, « un endroit plus propice au travail de la pensée » (p.9) que le Pakistan, alors en guerre civile. Entre 1995 et 1997, elle y a observé les pratiques de piété

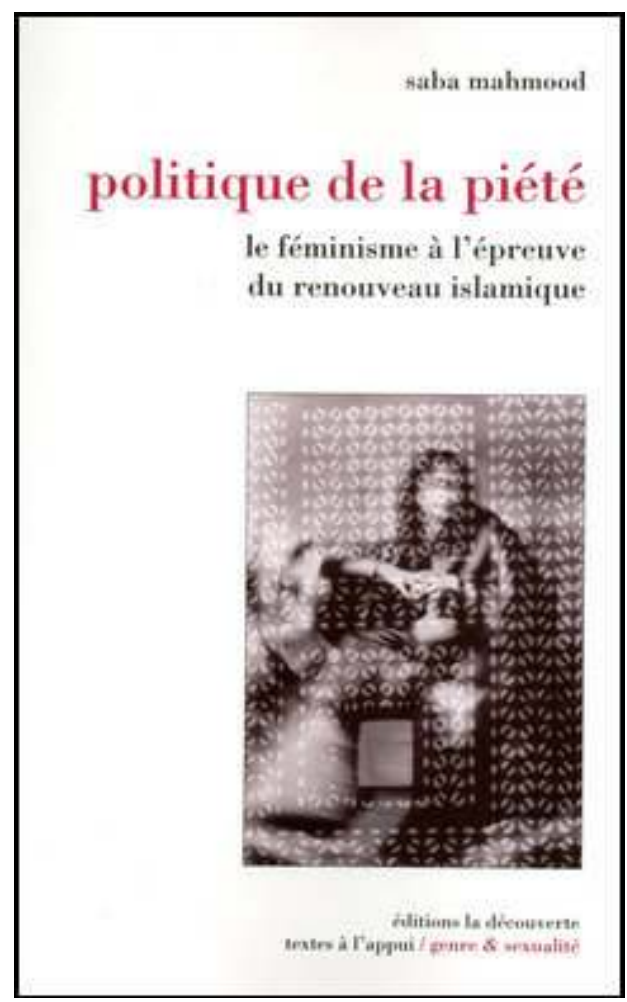
quotidiennes de femmes musulmanes engagées dans le mouvement de renouveau islamique, au sein de six mosquées à la sociographie variée. Ces femmes participent plus précisément du mouvement des mosquées (MdM) ou mouvement de la da 'wa (l'appel à l'Islam), déjà très populaire à cette époque pour le devenir plus encore les années suivantes. Présenté dans le deuxième chapitre, le MdM se définit selon ses membres par une lutte contre la sécularisation, autrement dit contre la spécialisation des sphères d'activités, la « folklorisation » des rites et la réduction de ces derniers à de simples manifestations identitaires. Pour les participantes du MdM, en effet, chaque activité de la vie quotidienne doit être empreinte de valeurs islamiques, indépendamment de toute finalité extérieure (comme une revendication quelconque). Leur objectif n'est pas, par conséquent, d'imposer le respect des principaux rituels (ce qui est généralement fait), mais de faire en sorte que tous les aspects de la vie soient organisés de façon vertueuse et deviennent, par là, " un moyen de réaliser la volonté divine » (p. 76).

3 Parmi les particularismes qui traversent le féminisme, l'auteur observe que les appartenances religieuses ont rarement eu leur place, en raison du traitement que les religions ont depuis longtemps réservé aux femmes. Sur ce point, les féministes hégémoniques rejoignent souvent les libéraux séculiers, jusqu'à qualifier les croyantes, islamistes notamment, de "pions du patriarcat». Les femmes du MdM seraient, en étant présumées victimes de fausse conscience par ces derniers, des sujets qui ne se rendent pas compte du caractère inné et universel du désir de liberté. À cet endroit, Saba Mahmood entend défendre une analyse critique des présupposés libéraux qui font de la liberté le désir ultime de tout être humain, et qui rendent synonymes la capacité d'agir et l'opposition aux normes sociales. Ce renversement de perspective ne s'est pas fait sans difficulté ni sans «un certain degré d'autoanalyse et de scepticisme par rapport à la certitude de [ses] propres engagements politiques » (p. 8). En effet, comme 
l'auteur l'expose dans le premier chapitre, le MdM pose un problème aux féministes, car il se fonde sur une tradition et des idéaux souvent associés à la domination masculine, la soumission féminine, la subordination et le conservatisme social. C'est à partir d'un appareillage théorique et conceptuel particulièrement fourni (performativité, normes, sujet, habitus, éthique) que Saba Mahmood étaye sa définition de la capacité d'agir. Elle considère que la rendre synonyme de résistance, ou d'émancipation, réduit sa portée heuristique. Il existe en effet de «multiples façons dont on habite les normes» (p. 32), parmi lesquelles une apparente passivité ou docilité. Elle précise que la capacité d'agir n'appartient pas en soi à l'individu, mais qu'elle résulte « de traditions discursives historiquement contingentes dans lesquelles elles [en l'occurrence, les femmes du MdM] se situent » (p. 57).

4 Les cours du MdM, étudiés au chapitre 3, sont dispensés par des da iyat (prédicatrices) autodidactes qui incarnent les grandes évolutions de la religion en Égypte, dont l'individualisation de la responsabilité morale en Islam et la critique des enseignements traditionnels de l'Islam qui ne s'adressent qu'aux élites (masculines). Divers éléments, comme l'alphabétisation croissante de la population égyptienne et l'importante diffusion de manuels doctrinaux sur l'Islam, conduisent les fidèles à adopter une position réflexive sur la meilleure manière de mettre en œuvre les préceptes islamiques dans leur vie quotidienne. Ce phénomène d'assouplissement des exigences doctrinales est connu sous le nom de talfiq. Saba Mahmood montre que la manière dont les da 'iyat usent des outils pédagogiques à leur disposition varient selon la classe sociale, le genre et les générations : si dans une mosquée fréquentée par les classes moyennes et supérieures, la da'iya s'appuie sur deux textes classiques du Coran, dans une mosquée fréquentée par les classes ouvrières et populaires, la da'iya mêle connaissances doctrinales et savoir populaire et se livre à des interprétations très libres des versets du Coran. Ce rapport différentiel aux textes sacrés interroge la dialectique de la tradition et de la modernité, dans la mesure où les façons d'« être moderne » sont «structurées et formées par des traditions historiques persistantes» (p. 175). Finalement, et malgré des interprétations différentes de la part des da 'iyat, c'est par la citation répétée des hadiths (actes du prophète compilés par les juristes musulmans) que ceux-ci acquièrent leur autorité de manière performative.

Dans les quatrième et dernier chapitres, l'auteur analyse la manière dont les femmes du MdM investissent les pratiques rituelles : celles-ci constituent à la fois une finalité (mettre en œuvre un soi pieux) mais aussi un moyen pour atteindre l'état de piété. La prière, par exemple, doit être accomplie dans un état de volonté particulier, qui n'est pas «naturel» mais qui résulte d'un «travail»: le désir de prier peut ainsi être "cultivé et renforcé» (p. 184). Ce dernier n'est donc pas «l'antécédent ni la cause de l'action morale ; il en est le produit » (p. 188) : en orientant tous ses actes vers le plaisir de Dieu, la fidèle acquiert l'aptitude à la prière régulière tout autant que la création d'un soi pieux. L'auteur propose ici de repenser le sens du rapport qu'entretiennent l'intériorité et l'extériorité (l'apparence et les pratiques corporelles, les rituels). Elle remet en cause l'idée d'une conscience qui aurait une existence propre, indépendamment des pratiques, et envisage l'extériorité comme constitutive de l'intériorité. Autrement dit, les comportements extérieurs contribuent sur le plan moral à former des individus : "C'est l'enchaînement des pratiques et des actions dans lesquelles on est engagé qui détermine les désirs et les émotions » (p. 233). En adoptant cette perspective, l'auteur montre que la capacité d'agir dans le cadre religieux est limitée, et s'exprime aussi dans la capacité à « endurer ». En prenant pour exemple le 
célibat vécu par une participante du MdM et par une «musulmane séculière » - bien que l'injonction au mariage soit déjà plus ou moins coercitive selon le sexe - l'auteur souligne que la première interprète le célibat comme une opportunité de cultiver sa patience (sabr) au regard de Dieu, alors que la seconde refuse cette passivité et s'en offusque. Pour l'auteur, la passivité des femmes du MdM devient alors une forme d'action: le sabr permet de vivre dans l'adversité et «fait entièrement partie d'un projet constructif » du soi pieux (p. 256).

6 Pour conclure, le travail de Saba Mahmood est remarquable à plusieurs égards. D'abord, pour le doute constant dont elle fait preuve face aux typologies dualistes. Ce faisant, elle revalorise toute la complexité du social en évitant les simplifications trop rapides (du type "passivité vs. résistance » ou «construction vs. déconstruction des normes »). Ensuite, pour traquer tout présupposé implicite dans l'interprétation des actions et des discours individuels, comme on l'a vu avec le désir inné pour la liberté. Enfin, mais non des moindres, pour sa rigueur méthodologique et la réflexivité dont elle fait preuve tout au long de l'ouvrage : elle adopte, en effet, une posture humble et (auto)critique « ouverte sur la possibilité d'être soi-même transformé dans le processus de confrontation de différentes visions du monde » (p. 63). Pour toutes ces raisons, lire la Politique de la Piété nous parait indispensable en sciences des religions, et en sciences humaines et sociales en général. 